\title{
A psicologia histórico-cultural em diálogo: \\ a trajetória de pesquisa do GEPSA ${ }^{\star}$
}

\author{
Maria de Fátima Cardoso Gomes, ${ }^{\star}$ Vanessa Ferraz Almeida Neves, Isabela Costa Dominici \\ Universidade Federal de Minas Gerais, Belo Horizonte, MG, Brasil
}

\section{Resumo}

Neste texto apresentamos o Grupo de Estudos e Pesquisas em Psicologia Histórico-cultural na Sala de Aula (GEPSA), que tem como objetivos desenvolver ensino, pesquisa e extensão sobre linguagem, discurso, cognição social, cultura e inclusão na sala de aula. Em busca de uma abordagem teórico-metodológica coerente com os pressupostos da psicologia histórico-cultural, estabelecemos um diálogo com a etnografia interacional. Apresentamos aqui uma investigação conduzida em uma turma com crianças de cinco anos de idade de uma Unidade Municipal de Educação Infantil de Belo Horizonte, Brasil. O evento de letramento que analisamos foi denominado "O que tem no meio do mar, do céu, do rio e do sol". A análise desse evento nos possibilitou evidenciar como as crianças trazem para a escola o que sabem das palavras, quantas coisas conhecem sobre esses conceitos, porém pela mediação da escola podem constituir novas identidades, novos conhecimentos de si e do mundo.

Palavras-chave: psicologia histórico-cultural; GEPSA; crianças; eventos de letramentos.

\section{Cultural-Historical Psychology in dialogue: the trajectory of GEPSA's research}

\begin{abstract}
This text introduces the Cultural-Historical Psychology Classroom Research Group (GEPSA) that has as goals to study language, discourse, social cognition, culture and inclusion within classrooms. We link Cultural-Historical Psychology and Interactional Ethnography searching for a theorical and methodological coherence to conduct our researches. We present an investigation within a six-child classroom in Belo Horizonte, Brazil. We analyzea literacy event called "What is in the middle of the ocean, heaven, river and sun". The analysis demonstrates how children bring to school what they know about the words and its concepts. Through school mediation, children can constitute new identities, and new knowledge about themselves and the world.
\end{abstract}

Keywords: Cultural-Historical Psychology; GEPSA; children; literacy events.

O objetivo deste texto é apresentar nosso grupo e as perspectivas teóricas e metodológicas que norteiam nossas pesquisas. O Grupo de Estudos e Pesquisa em Psicologia Histórico-Cultural na Sala de Aula (GEPSA) foi formado em 2006 na Faculdade de Educação da Universidade Federal de Minas Gerais, sob a liderança da professora doutora Maria de Fátima Cardoso Gomes, com o objetivo de desenvolver estudos, pesquisa e extensão sobre linguagem, discurso, cognição social, cultura e inclusão na sala de aula. Desde então, parcerias com diversos pesquisadores, nacionais e internacionais, tem sido consolidada.

A questão norteadora dos nossos estudos é "como nos apropriamos do mundo?". Tal questão se desdobra em outras, mais específicas: "como estudantes e professores transformam atividades de leitura, escrita e cálculos em funções mentais, em desenvolvimento mental e cultural?"; "como esses sujeitos constroem os eventos de leitura e escrita?" e "quais sentidos e significados são construídos para esses eventos?".

A perspectiva teórico-metodológica que adotamos tem sua base na psicologia histórico-cultural. Compreendemos que o desenvolvimento individual, ou a apropriação da realidade, é construído na relação dialética entre

\footnotetext{
^ Grupo de estudos e pesquisas em psicologia histórico-cultural na sala de aula (GEPSA), Coordenado por Maria de Fátima Cardoso Gomes. As autoras agradecem ao auxílio financeiro da CAPES/CNPq.

$\star \star$ Endereço para correspondência: Universidade Federal de Minas Gerais, Faculdade de Educação, Departamento de Ciências Aplicadas a Educação. Av. Antônio Carlos-6627 Pampulha/B.H./M.G. sala 1622 - Pampulha. CEP: 31270-901 - Belo Horizonte, MG - Brasil. E-mail: mafacg@gmail.com, vfaneves@gmail.com, isabelacd@hotmail.com
}

as pessoas, crianças e adultos, que acontece nos níveis interpessoal e intrapessoal. Para Vigotski (1993[1934]), o sujeito é social e se individualiza ao apropriar-se do mundo, que é externo ao sujeito. Angel Pino (2000) defende que esse processo de individualização pode ser compreendido como aquele em que o indivíduo torna-se humano e desenvolve sua subjetividade, ou seja, toda função psicológica foi anteriormente uma relação entre pessoas. Dessa forma, podemos dizer que o sujeito, ao apropriar-se de um significado social, pode atribuir individualmente sentidos aos eventos que o cercam.

Em particular, nós nos interessamos pelos sentidos e significados atribuídos à linguagem escrita no contexto escolar. Sentidos e significados que são construídos nas e pelas interações que acontecem na sala de aula a partir das práticas culturais do grupo, com a mediação da linguagem. Tal linguagem é entendida como uma prática social, como linguagem em uso, um mediador semiótico, que pode ser verbal, coverbal e não verbal (GUMPERZ, 2002). Linguagem que produz e é produzida pelas e nas culturas, por meio das enunciações das pessoas, daquilo que dizem, fazem e sentem.

Consideramos, assim, que o processo de escolarização envolve a construção de subjetividades, em que a criança assume o papel social de aluno. Packer e Goicoechea (2000) argumentam que a pessoa humana é construída histórica e socialmente em um contexto social, sustentada e transformada em atividades práticas, formada em relações de desejo e de reconhecimento que 
podem causar uma divisão ou estranhamento na própria pessoa, motivando uma busca por sua própria identidade. Portanto, "seres humanos são formados e transformados em relacionamentos com os outros, no desejo por reconhecimento, nas práticas de uma comunidade em particular, e no modo em que são divididas e iniciam a luta pela própria identidade" (PACKER; GOICOECHEA, 2000, p. 234, tradução nossa). O ser humano é posicionado pela comunidade da qual participa e, igualmente, se posiciona em relação às formas de pertencimento colocadas. Packer e Goicoechea (2000, p. 234, tradução nossa) defendem ainda que:

[...] a aprendizagem - construção de conhecimentos ou de entendimentos - é uma parte integral de mudanças ontológicas maiores que derivam da participação em uma comunidade. Uma comunidade de prática transforma a natureza em cultura; ela postula práticas circunscritas para seus membros, cria maneiras possíveis para constituir-se em ser humano, maneiras possíveis de como apropriar-se do mundo - primeiramente apreendido com o corpo e depois com instrumentos e símbolos - por meio da participação em práticas sociais e do relacionamento com outras pessoas.

Concordamos com os autores acima citados, entendendo que não apenas "entrar" na escola, mas pertencer a um determinado grupo como um membro, implica um processo de ganhos e perdas. Ganhos de aprendizagem e de desenvolvimento, de construção de novos posicionamentos sociais e também perdas e/ou diferenciações em relação às experiências em outros contextos sociais, como, por exemplo, a família. A experiência da infância no contexto escolar transforma a criança que, por sua vez, forja sua identidade como aluno e busca ser reconhecida nesse processo. Consequentemente, estar na escola transcende um processo simplesmente cognitivo.

Em busca de uma abordagem teórico-metodológica coerente com os pressupostos da psicologia histórico-cultural, estabelecemos um diálogo com a etnografia interacional (CASTANHEIRA et al., 2001), campo teórico que articula a antropologia, a sociolinguística interacional e a análise crítica do discurso. Como já afirmamos:

Na visão da etnografia interacional, a aprendizagem também se faz tanto social quanto individualmente, porém essa visão amplia a concepção de aprendizagem ao introduzir a noção das salas de aula como culturas e, assim, a aprendizagem vai além dos conteúdos escolares, mas refere-se também aos direitos e deveres, normas e expectativas e resultados para todos os envolvidos nas práticas culturais das salas de aulas (GOMES; NEVES; OLIVEIRA, 2012, p. 81).

As linguagens verbal, coverbal e não verbal são vistas aqui como linguagem em uso, como discurso. Tal concepção é desenvolvida por autores como Bakthin (2003) e Agar (1996). De acordo com Agar (1996), há uma íntima relação entre linguagem e cultura, expressa no neologismo languaculture. Segundo esse autor, langua, em languaculture, significa discurso, não apenas palavras e sentenças. E culture, no termo languaculture, diz respeito aos significados construídos, indo, portanto, além do que o dicionário e a gramática podem oferecer (AGAR, 1996, p. 96). Agar parte do princípio de que é a linguagem quem cria cultura, mas a cultura também cria linguagem, e os dois conceitos, agora reunidos em um só, criam identidades múltiplas que sempre se modificam. As relações entre linguagem e cultura são compreendidas como relações entre o discurso e os sentidos e significados construídos nos e pelos grupos culturais.

Ao longo do processo de consolidação das pesquisas no GEPSA, estabelecemos articulações com outros campos como os novos estudos sobre o letramento (STREET, 1984), a sociologia da sala de aula (CHARLOT, 2001; LAHIRE, 1997), a pedagogia de Paulo Freire (1968) e a sociologia da infância (CORSARO, 2005; SARMENTO, 2008). Tais articulações têm se assentado na busca de um refinamento em nossas discussões e análises, construindo pontes que nos ajudem a entender melhor as salas de aula investigadas e que não foram, talvez, suficientemente desenvolvidas nos estudos da psicologia histórico-cultural.

Assim é que, por exemplo, o conceito de Zona de Desenvolvimento Iminente (VIGOTSKI, 1995[1983]; PRESTES, 2012) nos ajuda a entender o papel de mediação do outro no processo de desenvolvimento da pessoa. Vigostki afirma que essa zona é definida por aquilo que a criança consegue fazer com a ajuda do adulto e/ou do companheiro mais capaz. Entendemos, a partir das reflexões de William Corsaro (2005) no campo da sociologia da infância, que essa Zona poderia ser compreendida também como aquilo que a criança consegue fazer com a ajuda de outros, sejam eles adultos ou crianças, mais ou menos experientes. Dessa maneira, a apropriação de sentidos e significados dá-se de maneira individual e coletiva tanto no âmbito da cultura mais ampla, quanto no contexto mais específico da cultura de pares. Nesse sentido, vimos adotando a concepção de Zona de Desenvolvimento Iminente como um espaço e tempo de compartilhamento de saberes, de construção democrática de conhecimentos.

Assinalamos, brevemente, os diálogos que estabelecemos com algumas perspectivas teórico-metodológicas. $\mathrm{Na}$ seção a seguir, exploramos esses diálogos na análise de um evento de letramento em uma turma de educação infantil.

\section{Linguagem em uso e a produção de sentidos e significados sobre a linguagem escrita: um estudo de caso}

Apresentamos aqui uma investigação conduzida por Dominici (2014) em uma turma com crianças de cinco anos de idade de uma Unidade Municipal de Educação Infantil de Belo Horizonte. A pergunta principal da pesquisa referiu-se à produção de sentidos e significados construídos pelos sujeitos (crianças e professora) sobre a linguagem escrita no contexto da educação infantil. Entendemos que o processo de apropriação da linguagem escrita está intimamente relacionado à construção de identidades letradas, ou seja, identidades nas quais as práticas sociais de leitura e escrita tornam-se centrais para cada uma das crianças e também para seu grupo geracional (CASTANHEIRA; NEVES; GOUVÊA, 2013). Identidades, portanto, que relacionam o contexto escolar com outros contextos sociais, como a família e a comunidade na qual esses sujeitos estão inseridos. Dessa forma, nós procuramos contribuir com o amplo debate 
educacional relativo à centralidade da escrita nessa etapa educacional (por exemplo, BRANDÃO; ROSA, 2010; BRASIL, 2009a; 2009b; CAMPOS, 2009; KRAMER, 2010; NEVES; GOUVÊA; CASTANHEIRA, 2011).

A Tabela 1, a seguir, representa o processo de construção dos dados da pesquisa em que a presente análise se insere.

Tabela 1: Processo de construção dos dados da pesquisa.

\begin{tabular}{|c|c|c|c|}
\hline Escola & Características & $\begin{array}{l}\text { Período de } \\
\text { Observacão }\end{array}$ & Construção dos dados \\
\hline $\begin{array}{l}\text { Unidade Municipal de } \\
\text { Educação Infantil } \\
\text { (Belo Horizonte) }\end{array}$ & $\begin{array}{c}21 \text { crianças } \\
\text { (12 meninas e } 9 \\
\text { meninos) } \\
2 \text { Professoras } \\
1 \text { Professora Regente } \\
\text { (15 horas com a turma) } \\
1 \text { Professora que } \\
\text { desenvolve um projeto } \\
\text { de música } \\
\text { (5 horas com a turma) }\end{array}$ & $\begin{array}{l}\text { Fevereiro/Julho de } 2013 \\
65 \text { dias de observação } \\
\text { (aproximadamente } 200 \\
\text { horas de filmagens) }\end{array}$ & $\begin{array}{l}\text {-Observação } \\
\text { Participante } \\
\text {-Anotações no Diário } \\
\text { de Campo } \\
\text {-Gravações em áudio e } \\
\text { vídeo } \\
\text {-Fotografias do } \\
\text { cotidiano escolar }\end{array}$ \\
\hline
\end{tabular}

A sala de aula observada denominou-se " $A$ linda Rosa Juvenil" a partir de uma votação feita com as crianças da turma. ${ }^{1}$ A rotina construída nessa sala de aula envolve uma grande ênfase nas brincadeiras que, ora são orientadas pelas professoras, ora acontecem entre as crianças com os brinquedos da sala de aula. Estão presentes também momentos relativos à leitura/contação de histórias, uma vez por semana, em que a professora regente faz a leitura de livros de literatura infantil e pede que as crianças registrem a história contada/ lida com desenhos. Durante a realização da pesquisa foi possível observar sete desses momentos. Há também os momentos em que uma das professoras desenvolve um projeto de musicalização com as crianças, em particular a partir de um trabalho sobre a vida e obra de Vinicius de Moraes. A professora conduzia a aula tocando o violão ou brincando com as crianças, tendo a música como mediador semiótico, e, posteriormente, pedia às crianças

\footnotetext{
Esta escolha foi feita a partir de uma conversa e registro no quadro de brincadeiras que as crianças conheciam e gostavam. É interessante pontuar a escolha de um nome "feminino" para a turma, o que nos remete a relações de gênero sendo construídas naquele contexto, configurando uma predominância de um "ambiente feminino" no âmbito da educação infantil (AFONSO, 1995). Uma hipótese que podemos levantar em relação a essa escolha refere-se ao número de meninas na turma. Poderíamos também nos perguntar sobre a reação dos meninos acerca do nome escolhido. Tal análise, entretanto, foge aos objetivos imediatos do presente texto.
}

que registrassem/desenhassem em folha a situação vivenciada com a música. Um tempo significativo da rotina da turma relaciona-se diretamente com os momentos de lanche e jantar (40 minutos do tempo total) e com o recreio (aproximadamente 30 minutos do tempo total).

O evento de letramento (HEATH, 1983) que analisaremos foi denominado "O que tem no meio do mar, do céu, do rio e do sol". A escolha desse evento em particular considerou seu potencial expressivo (STRIKE, 1974), ou seja, o que tal análise nos possibilitou compreender sobre os sentidos e significados da linguagem escrita para a turma investigada. Assim, o evento em questão, ocorrido no dia 25 de fevereiro, relaciona-se com outros eventos de letramento que ocorreram ao longo de 2013, em particular com aqueles dos dias 19 e 20 de fevereiro. Esses eventos estão sublinhados na Figura 1, logo abaixo. 
Enquanto as crianças desenhavam, elas podiam visualizar os personagens no livro que estava à disposição delas. As crianças se revezavam para olhar o livro. Em um determinado momento, a pesquisadora se aproximou de Laura, criança que estava com o livro nas mãos, e perguntou:

Dominici: Você já leu esse livro?

Laura: Não/ Eu ainda não sei ler!

A pesquisadora fez essa pergunta partindo do pressuposto de que essa criança havia sim lido o livro, observado as imagens, estimulado suas emoções e a imaginação, adquirido vocabulário, juntamente com a professora e com o grupo enquanto ouvia a história. No entanto, mesmo tendo participado da leitura/contação da história, essa criança afirma: "Não/ Eu ainda não sei ler!" A surpresa demonstrada pela exclamação ao final da frase nos indica que, para ela, ler é saber decodificar e compreender o seu conteúdo. Ou seja, para Laura, ler adquire os sentidos que a cultura escolar também reconhece. Nesse sentido, escutar a história não é o mesmo que ler individualmente a escrita presente nas páginas do livro.

Laura retoma o seu desenho, junto com seus colegas. Nesses desenhos encontravam-se representações de baleias, baiacus, cavalos marinhos etc. Essa forma de registro é um indício de que as crianças fizeram relações com os significados e sentidos que a palavra "mar" remetia a elas. A professora, após cada criança finalizar seu desenho, exercia o papel de escriba, registrando os nomes dos personagens desenhados. Por fim, após esse registro, a professora autorizou que as crianças levassem seus desenhos para casa.

No dia 20 de fevereiro de 2013, a professora recontou a história e propôs novamente que as crianças registrassem a narrativa em uma folha, solicitando que elas recortassem os desenhos e os colassem em um cartaz cujo título era "O que tem no meio do mar?” (Figura 2).

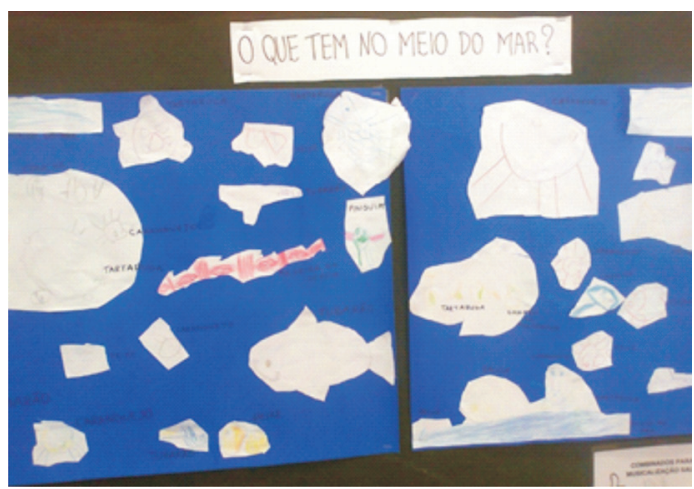

Figura 2: Mural "O que tem no meio do mar?"

O mural, nesse caso, foi o suporte para a produção do gênero textual cartaz pelas crianças e professora. Todos os desenhos foram nomeados pelas crianças e registrados pela professora que, como no dia anterior, exerceu o papel de escriba do grupo. Afixar os desenhos de todo o grupo em um local de destaque na sala de aula deu visibilidade à importância atribuída naquele contexto à produção das crianças e também ao evento que estava em processo de construção.
Já no dia 25 de fevereiro de 2013, a professora fez referência à história contada nos dias anteriores, mas pontuou que o trabalho desse dia não seria como o dos outros. Dessa vez, ela propôs que as crianças trabalhassem em grupos de quatro crianças cada para registrarem com desenhos em uma folha de cartolina o que havia no meio do "mar", do "céu", do "rio", e do "sol" (Figuras $3,4,5$ e 6$)$.

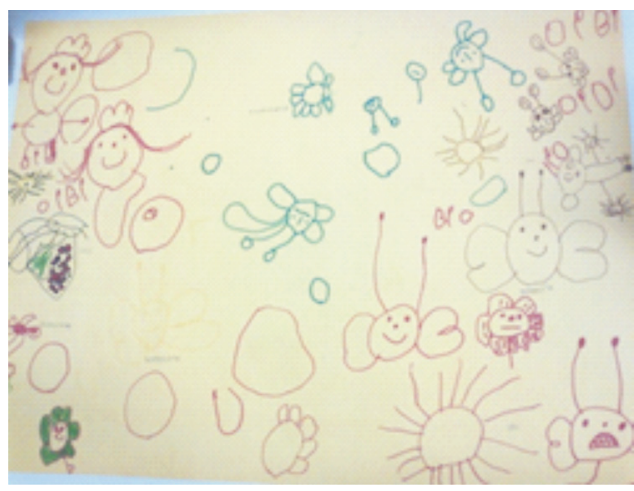

Figura 3: Registro do que há no meio do céu

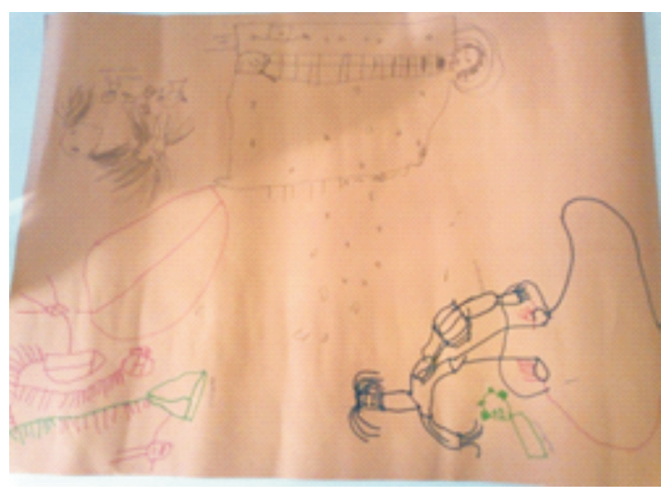

Figura 4: Registro do que há no meio do sol

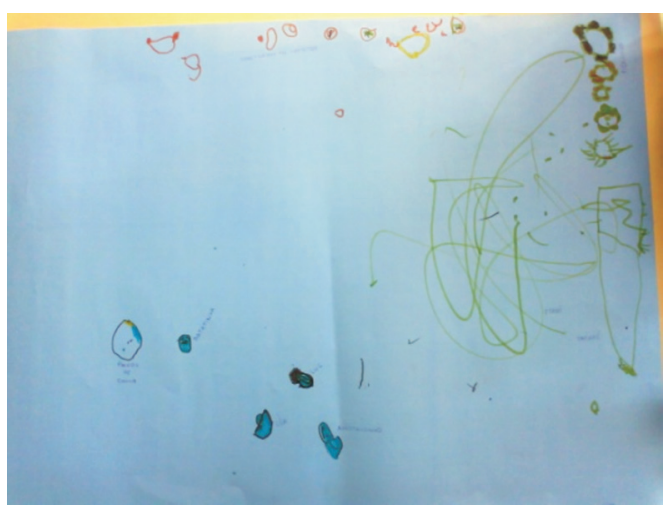

Figura 5: Registro do que há no meio do rio 


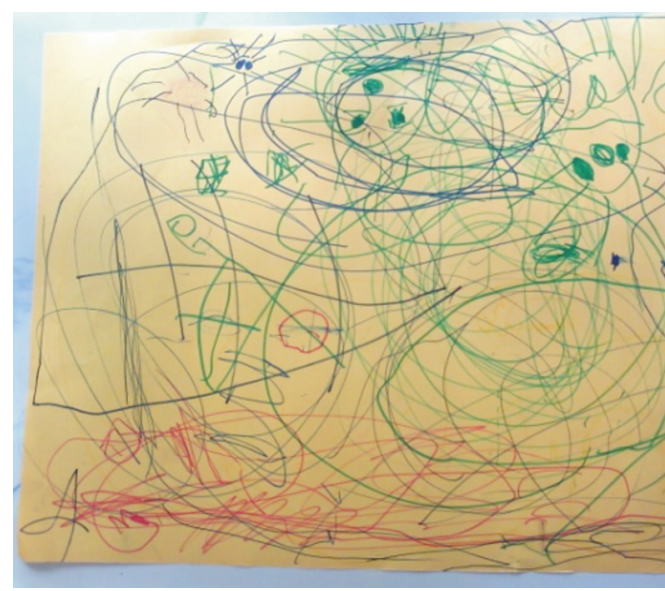

Figura 6: Registro do que há no meio do mar

Figuras 3, 4, 5 e 6: Desenhos coletivos das crianças.

Em conversa informal com a professora, para compreender a proposta do trabalho, a pesquisadora pergunta se a produção das crianças seria também colocada no mural. É perceptível, aqui, a expectativa da pesquisadora construída nos dias anteriores, em que tornar visível as produções das crianças estava se constituindo como uma rotina cultural daquele grupo. A professora comenta que a proposta desse trabalho seria confeccionar um livro e ensinar às crianças as vogais presentes no meio das palavras - "mar", "céu", "rio", "sol" e "lua". Tal proposta, entretanto, não se concretizou: os desenhos coletivos foram guardados no armário da professora, que não os mencionou em outros momentos, bem como não houve uma explicitação das vogais para as crianças. Podemos nos perguntar sobre os motivos que levaram à não concretização da proposta.

$\mathrm{Na}$ turma investigada, a professora organizou diversos eventos de letramento com as crianças, como fica claro na Figura 1. Entretanto, há uma tensão relativa à forma "como" a linguagem escrita deve ser trabalhada com crianças de cinco anos. Tensão que está presente no discurso acadêmico, nos documentos normativos e orientadores emitidos pelo Ministério da Educação e também nas práticas educativas na educação infantil. Talvez tenha sido esse o motivo pelo qual a professora não concretizou a sistematização das vogais com as crianças. ${ }^{2}$

Sozinhas, elas ainda não poderiam fazer análises dos grafemas e fonemas, mas sim dos significados daquelas palavras: foi uma análise semântica o que as crianças realizaram ao representarem, por meio dos desenhos e de algumas letras, os significados do que ou de quem vive nos espaços do "mar", "céu", "rio" e "sol". As crianças, em um esforço coletivo e através de um mediador semiótico (o desenho), construíram sentidos e significados para a solicitação da professora. Por outro lado, para uma análise das relações grafema-fonema, as crianças necessitariam da mediação da professora para provocar zonas de desenvolvimento iminentes para que pudessem identificar as vogais que estão no meio das palavras já apresentadas.

\footnotetext{
Esta proposta de trabalho, a partir de uma sistematização das vogais, revelaria uma concepção associacionista de ensino e aprendizagem da linguagem escrita. Por outro lado, a leitura sistemática no cotidiano da turma deixa transparecer uma concepção contextualizada e situada do ensino e aprendizagem da língua escrita. A prática educativa oscila entre essas concepções.
}

Uma forma de mediação possível seria o uso de um mediador semiótico poderoso, a linguagem musical, que, aliado à narração de história, à apresentação dos gêneros textuais e dos suportes necessários à utilização social da linguagem escrita, poderia possibilitar às crianças a compreensão dos significantes - fonemas das vogais - e dos motivos para a escrita dessas letras. Quanto ao mediador semiótico a que nos referimos, temos na música de Rubinho do Vale um exemplo interessante. Na música "AEIOU", o compositor brinca com as vogais. $\mathrm{O}$ próprio título da música já seria um mediador, uma pista significativa para que as crianças compreendessem o objetivo da professora.

\author{
AEIOU \\ Rubinho do Vale \\ No meio do mar tem A \\ No meio do céu tem $\mathrm{E}$ \\ No meio do rio tem I \\ No meio do sol tem $\mathrm{O}$ \\ No meio da lua tem $U$ \\ No meio da lua tem $U$ \\ E no meu coração tem amor pra chuchu.
}

Dessa forma, as professoras da educação infantil podem e devem usar textos reais e significativos que circulam em nossa sociedade para, de forma lúdica, apresentar o mundo da escrita às crianças sistematicamente com o objetivo de inseri-las nesse mundo para que se tornem leitores fluentes e amantes da leitura.

\section{Notas finais}

Segundo Street (1984), o que conta como letramento varia em diferentes grupos sociais, contextos educacionais e salas de aula. Nessa turma, no início do ano começou a ser construída uma representação da linguagem escrita intimamente relacionada com práticas culturais significativas para o grupo: leitura e reconto de livros de literatura infantil, desenhos relacionados a essas narrativas e acompanhados do uso da linguagem escrita para registro do que foi produzido pelas crianças, bem como para dar o título ao mural da turma.

A análise do evento "O que tem no meio do mar, do céu, do rio e do sol" nos possibilitou evidenciar, através do diálogo entre a psicologia histórico-cultural e a etnografia interacional, como as crianças trazem o que sabem das palavras para os cartazes, quantas coisas conhecem sobre esses conceitos. Porém, é função da escola ensinar-lhes para além do que já sabem - constituindo novas identidades, novos conhecimentos de si e do mundo.

\section{Referências}

AFONSO, M. L. Gênero e processo de socialização em creches comunitárias. Cadernos de Pesquisa, São Paulo, n. 93, p. 12-21, maio 1995.

AGAR, M. Language Shock: understanding the culture of conversation. New York: Harper Collins, 1996.

BAKHTIN, M. Gêneros do discurso. In: Estética da criação verbal. São Paulo: Martins Fontes, 2003. p. 261-270.

BRANDÃO, A. C. P.; ROSA, E. C. S. (Org.). Ler e escrever na educação infantil. Belo Horizonte: Autêntica, 2010.

Fractal, Rev. Psicol., v. 27 - n. 1, p. 44-49, 2015 
BRASIL. Ministério da Educação. Diretrizes Curriculares Nacionais para a Educação Infantil. Resolução do CNE/CEB $\mathrm{N}^{\circ} 5$, de 17 de dezembro de 2009a.

BRASIL. Ministério da Educação. Programa Currículo em Movimento. Brasília, DF: Secretaria de Educação Básica, 2009 b.

CAMPOS, M. M. Ensino Fundamental e os desafios da Lei 11.274/2006. Anos Iniciais do Ensino Fundamental - TV Escola/ Salto para o Futuro, Brasília, ano XIX, n. 12, p. 10-16, set. 2009.

CASTANHEIRA, M. L. et al. Interactional Ethnography: an approach to studying the social construction of literate practices. Linguistics and Education, [S.1.], v. 11, n. 4, p. 353-400, 2001.

CASTANHEIRA, M. L.; NEVES, V. F. A.; GOUVÊA, M. C. $\mathrm{S}$. Eventos interacionais e eventos de letramento: um exame das condições sociais e semióticas da escrita em uma turma de educação infantil. Cadernos. CEDES, Campinas, v. 33, n. 89, jan./abr. 2013.

CORSARO, W. The Sociology of childhood. 2nd ed. London: Sage, 2005

CHARLOT, B. (Org.). Os jovens e o saber: perspectivas mundiais. Porto Alegre: Artmed, 2001.

DOMINICI, I. A educação infantil e os eventos de letramentos em uma turma de 5 anos. Dissertação (Mestrado)-Faculdade de Educação, Universidade Federal de Minas Gerais., Belo Horizonte, 2014.

GOMES, M. F. C.; NEVES, V. F. A.; OLIVEIRA, L. S. Aproximações entre a Psicologia Histórico-cultural e a Etnografia Interacional. Juiz de Fora: UFJF, 2012.

GUMPERZ, J. J. Convenções de contextualização. In: RIBEIRO, B. T.; GARCEZ, P. M. (Org.). Sociolinguística Interacional. 2. ed. São Paulo: Loyola, 2002. p. 149-182.

HEATH, S. B. Ways with words: language, life, and work in communities and classrooms. New York: Cambridge University Press, 1983.

KRAMER, S. O papel da Educação Infantil na formação do leitor: descompassos entre as políticas, as práticas e a produção acadêmica. In: FRADE, I. C. A. et al.(Org.). Convergências e tensões no campo da formação e do trabalho docente. Belo Horizonte: Autêntica. 2010. p. 111-133.

LAHIRE, B. Sucesso escolar nos meios populares: as razões do improvável. São Paulo: Ática, 1997.

NEVES, V. F. A.; GOUVÊA, M. C. S.; CASTANHEIRA, M. L. A passagem da educação infantil para o ensino fundamental: tensões contemporâneas. Educação e Pesquisa, São Paulo, v. 37, n. 1, p. 121-140, jan./abr. 2011.

PACKER, M. J.; GOICOECHEA, J. Sociocultural an Constructivist Theories of Learning: Ontology, just not Epistemology. Educational Phychologist, v. 35, n. 94, p. 227$241,2000$.

PINO, A. O social e o cultural na obra de Vigotski. Educação \& Sociedade, Campinas, v. 21, n. 71, p. 45-78, jul. 2000.

PRESTES, Z. R. Quando não é quase a mesma coisa: Traduções de Lev Semionovitch Vigotski no Brasil. Campinas: Autores Associados, 2012.

SARMENTO, M. Sociologia da Infância: correntes e confluências. In: SARMENTO, M.; GOUVÊA, M. C. S. (Org.).
Estudos da infância: educação e práticas sociais. Petrópolis, RJ: Vozes, 2008. p. 17-39.

SHERY, K. Sou a maior coisa que há no mar. São Paulo: Rocco, 2010.

STREET, B. Literacy in theory and practice. Cambridge: Cambridge University Press, 1984.

STRIKE, K. A. On the expressive potential of behaviorist language. American Educational Research Journal, v. 11, n. 2, p. 103-120, 1974.

VIGOTSKI, L. S. Obras Escogidas (1983). Madrid: Aprendizage, 1995. v. 3.

VIGOTSKI, L. S. Obras Escogidas (1934). Madrid: Aprendizage, 1993. v. 2.

Recebido em: 29 de agosto de 2013 Aceito em: 29 de outubro de 2014 